\title{
Perils of substandard and counterfeit drugs better medicines for better patient care
}

Titus De Silva Q.S.M.

Former head of the National Drug Quality Control Laboratory, Ministry of Health Sri Lanka

Correspondence author email: titusdesilva@yahoo.com

\begin{abstract}
Proliferation of sub-standard and counterfeit drugs has become a global issue. The World Health Organisation (WHO), the governments, drug regulatory authorities, patient groups and manufacturers of genuine drugs have been devising ways and means to combat this crime. Lack of pharmacovigilance systems in developing countries makes it difficult to track the spread of sub-standard and counterfeit drugs. According the WHO, $10 \%$ of world drug supply is counterfeit. Most of the counterfeit drugs originate in less developed countries. The WHO has developed guidelines to establish national strategies and specific measures to control this menace. Therefore, drug regulatory authorities, patient groups, healthcare organisations and the manufacturers of genuine drugs should join forces and develop effective means to spread this global problem.
\end{abstract}

\section{Introduction}

There has been a growing concern during the past decade regarding substandard and counterfeit drugs and it has become a global issue. According to the World Health Organisation (WHO), 10\% of world's drug supply is counterfeit. In 2005, the sales of counterfeit drugs amounted to US \$39 billion and in 2010 it was estimated at $\$ 75$ billion, a $90 \%$ increase. $60 \%$ of counterfeit drug supply cases originate in less developed countries where $25 \%$ of them are counterfeit $^{1}$. This problem has received the attention of the WHO, drug regulatory authorities and manufacturers of genuine pharmaceutical products. At the $65^{\text {th }}$ World Health Assembly (WHA), an Executive Board recommended creating a mechanism for countries to work together on resolving the problem of substandard drugs. The WHO hopes to ensure the quality of drugs by urging countries to invest resources to prevent the growth of substandard and counterfeit drugs ${ }^{2}$.

Substandard drugs are genuine products that have not passed quality criteria established previously for each product. A distinction must be made between substandard drugs produced as a result of a genuine failure of Good Manufacturing Practices (GMP) and those made deliberately for profit. However both can have serious consequences. On the other hand counterfeit drugs are those, the identity and or the origin of which has been deliberately and fraudulently mislabelled as genuine drugs ${ }^{3}$. 


\section{Prevalence}

It is difficult to obtain accurate data on the extent of substandard and counterfeit drugs in the world. Data has been interpreted uncritically, some are inaccurate and do not consider generalisations about epidemiology of substandard medicines. Although the WHO maintains a database on counterfeit drugs, only $5-10 \%$ of 191 member states report cases of counterfeit drugs. Between 1982 and 1999, the WHO received 771 reports and of these $48.4 \%$ was from the west pacific region with most products being labelled as anti-infective. Counterfeit reports from 20 countries between January 1999 and October 2000 revealed that $60 \%$ of counterfeit medicines occurred in developing countries and $40 \%$ in industrial countries $^{4}$. Largest producers of counterfeit medicines are based in China, India, South East Asia, Nigeria, Russia, Mexico, Brazil and Latin America ${ }^{1}$.

According to a survey carried out in 2011 by the Pharmaceutical Security Institute (PSI), a non-profit organisation dedicated to protect the public health sharing information on counterfeiting of pharmaceuticals, 954 products were identified in Asia, 381 in Latin America, 361 in Europe, 257 in Eurasia, 237 in North America, 128 in Near East and 64 in Africa ${ }^{5}$.

\section{Impact of substandard and counterfeit drugs}

There are numerous reports of serious adverse effects of substandard and counterfeit drugs. Counterfeit drugs often contain substances injurious to health.
Following are some of the adverse effects of substandard and counterfeit drugs ${ }^{3,4}$.

- Adverse effects

Both substandard and counterfeit drugs can cause serious health hazards. These may be due to reduced stability and bioavailability, reduce concentration or lack of active ingredient, excessive dose, altered chemical characteristics and inappropriate packaging. Patients may experience allergic effects or other unexpected side effects due to the presence of potentially toxic active ingredient/ingredients or pathogenic contamination. There is also the possibility of treatment failure.

- Increased mortality and morbidity

- Loss of confidence in the health system and healthcare providers

- Financial loss for patients, their families, health systems and manufacturers and traders of genuine pharmaceuticals

- Waste of enormous human resources and financial outlay in development of medicines, establishing dosages, conducting clinical trials, discussing policy changes and manufacturing medicine

- Increase burden for healthcare providers, medicine regulatory authorities and policy officers caused by administering drug alerts, recalls and procuring replacements for substandard and counterfeit products. 
Reasons for the prevalence of substandard and counterfeit medication

Many factors contribute to the increased prevalence of substandard and counterfeit medication $^{3,6}$.

1. Quality is not demanded by the purchaser

Developing countries often procure medicines without adequate reference to quality standards. Local authorities do not always have ready access to required quality standards. Where drugs are purchased by non-governmental organisation on behalf of the government, tenders are issued without applying minimum quality assurance standards.

2. Limited ability to evaluate technical information

According to the WHO estimates only one in six countries have a fully functional drug regulatory authority. Developing countries often do not have drug testing facilities. Although drug registration is a pre-requisite for purchase in resource-limited countries, authorisation is granted following a brief review of submitted documents.

3. Lack of or limited pharmacovigilance system

The detection and prevention of adverse effects and other related problems is an essential component of any healthcare system. Such a system allows rapid communication of drug-related problems and recall of harmful drugs. Establishing a pharmacovigilance system involves cost which developing countries cannot often afford. In the absence of a pharmacovigilance system, greater and unfair burden is placed upon the medical staff to detect spurious drugs which are difficult to be detected by clinical checks

4. Diminishing number of manufacturing organisations that produce genuine key essential medicines. For example, the production of simple antibiotic penicillin has been abandoned in favour of cephalosporins, quinolones and macrolides.

5. Lack of understanding of the risk of substandard and counterfeit medicines. The risks of ignoring pharmacopoeial standards, insufficient or excess active ingredient, contamination, wrong or unfavourable excipients, stability issues and mislabelling are not fully understood.

6. Weak or absent drug regulatory authority.

7. Absence of legal mandate for licensing, manufacturing and import of drugs. GMP inspections conducted by unskilled personnel are often inefficient and ineffective.

8. Countries which export medicines may lack proper regulations or the regulations may not be enforced.

9. Proliferations of small pharmaceutical industries in the developing world.

10. Importing medicines is a complex process involving several intermediaries.

11. High demand for curative and preventive drugs and vaccines at low cost which exceed the supply.

12. High prices of genuine products in contrast to substandard and counterfeit 
products and inefficient cooperation among stakeholders.

13. Inappropriate and corrupt dealings in the tender process and offering tenders solely on the basis of lowest cost.

\section{Combatting the crime}

In 1988, World Health Assembly (WHA) called for the WHO to initiate a programme for the prevention and detection of export, import, smuggling of falsely labelled spurious counterfeit medicines. These efforts resulted in establishing the International Medical Products AntiCounterfeiting task force in 2006 (IMPACT) $^{7}$. In order to address the issue, effective collaboration between health authorities, police, customs, the judiciary, manufacturers, wholesalers, retailers, health professionals and patients is required.

The WHO has developed guidelines to establish national strategies as well as specific measures to be considered for combating counterfeit drugs ${ }^{8,9}$.

1.Strengthening political will and commitment

Political will and strong commitment by drug control authorities are essential to improve drug control and decrease the incidence of counterfeiting.

\section{Promulgate appropriate legislation}

Legislation relating to manufacture, importation, distribution, supply and sale of drugs should be reviewed regularly prohibiting all activities of counterfeit and substandard medicines. The measures should also include drawing and testing samples on arrival and during use.

3. Establish a drug regulatory authority

An efficient Drug Regulatory Authority (DRA) should be established and should be in constant touch with pharmaceutical industry as well as international organisations such as the WHO. The officers of the DRA should be trained in all aspects of their work as well as be able to identify, test, evaluate and report on the quality of drugs tested.

4. Develop standard operating procedures for skilled and competent drug inspectors for examination of documents, visual inspection and non-analytical procedure for detecting counterfeit medicines, sampling for analytical tests, methods for isolating and preventing the distribution substandard and counterfeit products, recording the information and seizing and destroying offending drugs.

\section{Enforcing drug control laws}

Genuine efforts has to be made for enforcing drug control laws and bringing those are involved in illicit activities to justice with severe penalties. All counterfeit and substandard drug incidences should be fully investigated. Sri Lankan authorities regularly blacklist pharmaceutical companies which violate procurement procedures and supply substandard medicines causing a shortage of essential drugs. This is a step in the right direction.

\section{Empower authorities}


Counterfeiting should be regarded as a serious offence and the judiciary should be empowered to impose harsh penalties in keeping with the offence. These cases should be given priority and handled expediently in order to confiscate, forfeit and destroy counterfeit medication.

\section{Foster partnership}

The pharmaceutical industry has an important role to play in the detection, control and eradicating counterfeit medicines. All manufacturers of genuine products should ensure that they have security systems in place to prevent counterfeiting their products, secure their own stock to prevent diversion to illegal manufacturers, monitor their products in the market and avoid promoting that may exceed the availability encouraging counterfeit production.

8.Independent check of quality of manufactured drugs.

9. Prices should not be the only criterion for approval of suppliers and products.

10. Conduct public awareness campaigns to educate the public on consequence of substandard and counterfeit drugs and their detection.

11. Reputed manufactures can help by reviewing the price strategy in order to make fraud less possible.

12. Eliminate corruption and conflict of interest at all levels

Corruption in all spheres of economy is an endemic feature in developing countries.
Procedures for dealing with tenders should be followed according to the rules without leaving room for corruption ${ }^{10}$. Prevalence of corruption and conflict of interest adversely affect the working of the DRA and law enforcement agency leading to the failure to arrest, prosecute and convict counterfeiters.

\section{Using advance technology}

Genuine pharmaceutical products manufacturers can support the DRA by using authentication techniques such as holograms, fluorescent markers, digital watermarks and radio frequency tags in their products. Boston University in collaboration with the Promoting the Quality of Medicines Programme has developed a portable, fieldbased instrument called PharmaCheck ${ }^{11}$ for assessing the quality of medicines in developing countries with increased accuracy, sensitivity and reliability. It uses fluorescence and imaging techniques to determine the concentration of the drug.

Counterfeit trade is a lucrative business and probably linked to organised crime, corruption, narcotics trade, the business interests of unscrupulous people and unregulated pharmaceutical companies ${ }^{3}$. Those who deliberately produce counterfeit and substandard medicines are criminals who have no regard for human life. We have a moral obligation to put the value of human life above rupees and cents.

\section{References}

1. Yankus W. Coming to a pharmacy near you. American Council on Science and Health. 2006. 
http://www.acsh.org/?s=counterfeit\&orderb $\mathrm{y}=$ relevance (accessed 12 November 2012)

2.Taylor N. Annual WHO meeting to tackle spread of sub-standard drugs. 2012. http://www.in-

pharmatechnologist.com/Processing/Annual

-WHO-meeting-to-tackle-spread-of-

substandard-drugs (accessed 29 October 2012)

3. Kelesidis T, Kelesidis I, Rafalidis PI and Falagas ME. Counterfeit or substandard antimicrobial drugs: A review of the scientific evidence. Journal of Antimicrobial Chemotherapy. 2007;60:214-236.

4. Newton P, Green MD and Fernandez FM. Impact of poor quality medicines in the developing world. Trends Pharmacological Sciences. 2010;31:99-101.

5.Global Voices. Tracking Counterfeit Medicines in the Developing World. 2012. http://globalvoicesonline.org/2012/08/30/inn ovations-to-track-counterfeit-medicines-in-

the-developing-world/ (accessed 18 November 2012

6. Coudron JM, Ford N. Henkens M, Mace C, Kiddle-Monroe R. and Pinet J. Substandard medicines in resource poor setting: A problem that can no longer be ignored. Tropical Medicine and International Health. 2008;13(8):1062-1072. 7. Clift C. Combating counterfeit, falsified and substandard medicines: Defining the way forward. Briefing paper. Chatham House. Royal Institute of International Affairs. 2010.

8. Department of essential drugs and other medicines. Counterfeit drugs: Guidelines for the development of measures to combat counterfeit drugs. World Health Organisation. 1999.

9. Wan PO. Too much too little or none at all. Lancet. 2001;3507,1904.

10. Wijewardena, A. Tenders fixed. SL flooded with low quality drugs. The Island. 2012;6:4.

11.Zaman, M. (n.d.). PharmaCheck: Counterfeit and substandard drug detector device for the developing world. Boston University.

http://www.bu.edu/bme/research/coulter/pro jects/pharmacheck/ (accessed November 2012) 